\title{
Research cuts hit the DNA business
}

\section{Makers of sequencing machines hope for profits in the clinic.}

\section{BY ERIKA CHECK HAYDEN}

A DNA sequencing machine is one of the most expensive lab purchases a biologist can make. So it is no surprise that, with research funding falling and worse times ahead, institutions are holding off buying the devices, leaving manufacturers feeling the pinch. After a round of gloomy third-quarter results, many makers of sequencing machines are now hoping that cost cutting and expansion into medical diagnostics will help them to prosper again.

Businesses that make sequencing machines or offer sequencing services rely heavily on custom from federally funded researchers, particularly those supported by the US National Institutes of Health (NIH). Although the NIH's 2011 budget is only $1 \%$ lower than it was in 2010 , pessimism about future government spending has led analysts to predict much bigger budget cuts in 2012 and 2013 - and that pessimism has also had an impact on sequencing companies' share prices (see 'Taking a hit').

"Owing to fears of lower government funding, institutions are certainly being more conservative with expenditures," says Shawn Levy, a geneticist at the HudsonAlpha Institute for Biotechnology, a genomics research centre in Huntsville, Alabama. Indeed, in a survey released on 24 October, $58 \%$ of 94 genome scientists polled by the online publication GenomeWeb and the Tokyo investment bank Mizuho Securities said that talk of austerity had caused them to delay lab purchases. Forty-two per cent said that they would probably not buy a new DNA sequencing machine in the next 12 months.

The bleak mood was clear in a round of financial results announced last week. Illumina of San Diego, California, which has captured the largest share of the sequencing market, said that its third-quarter profits were down by $43 \%$ compared with the same quarter of 2010 . The company blamed high costs and poorerthan-expected sales for the decline, and said that it will lay off some 200 workers, about $8 \%$ of its global workforce. Life Technologies of Carlsbad, California, said that its revenue grew by $7 \%$ in the last quarter, compared with the same period in 2010, helped

\section{$\rightarrow$ NATURE.COM}

Nature's genomics supplement: go.nature.com/ftkwlr

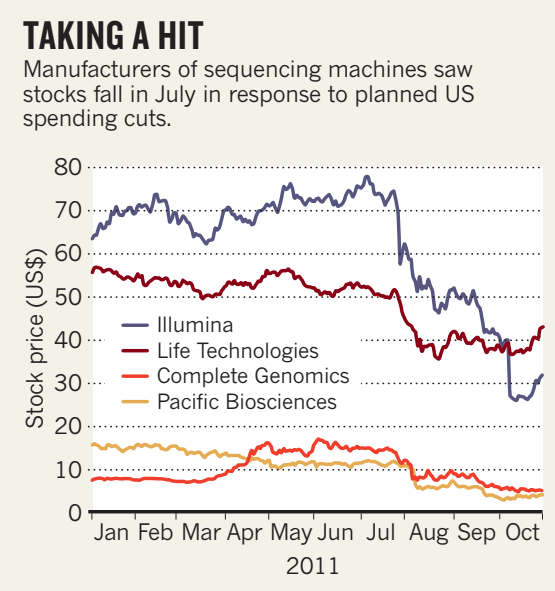

by strong sales of its Ion Torrent machines. But with an eye to difficult times ahead, the company has already laid off workers and carried out a round of cost cutting.

In September, Pacific Biosciences of Menlo Park, California, was forced to lay off 130 people $-28 \%$ of its staff - and reduce its overall 2011 earnings forecast. Other major genomics companies, such as California-based Complete Genomics of Mountain View and Affymetrix of Santa Clara, reveal their earnings this month.

In light of the dismal news, many sequencing companies are now eyeing new markets in biomedicine, where whole-genome sequencing is beginning to make inroads (see Nature 478, 22-24; 2011). Illumina, for example, will set up a business unit to promote the use of its tools in clinical diagnostics, and hopes that the imminent release of a lower-cost version of its MiSeq sequencing machine will boost sales.

Life Technologies, meanwhile, boasted that it would develop a genetic test to help predict an individual's response to a cancer drug that UK-based drug-maker GlaxoSmithKline is studying in phase III clinical trials. It also touted a US\$9-million deal to sell forensicanalysis systems in Russia, and underscored its double-digit growth in China, saying that it will increasingly turn its attention to Asia.

Dan Leonard, an analyst at health-care investment consultants Leerink Swann in Boston, Massachusetts, agrees that moving into the clinic is ultimately the sequencing industry's best hope for growth. 